Lomax M, Kapus J, Brown PI, Faghy M

Impact of weekly swimming training distance on the ergogenicity of inspiratory muscle training in well trained youth swimmers

Inspiratory muscle training and swimming

Mitch Lomax (corresponding author)

Department of Sport and Exercise Science

University of Portsmouth

Spinnaker Building

Cambridge Road

Portsmouth

Hampshire

UK

PO1 2ER

Tel: 02392845297

Email: mitch.lomax@port.ac.uk

Jernej Kapus

Laboratory of Biodynamics

Faculty of Sports

University of Ljubljana

Ljubljana

Slovenia

Tel: 0038615207796

Email: nejc.kapus@fsp.uni-lj.si

\title{
Peter Brown
}

English Institute of Sport 
Loughborough Performance Centre

$1^{\text {st }}$ Floor

Loughborough University

Epinal Way

Loughborough

UK

LE11 3TU

Tel: +44(0)7860 783007

Email: peter.brown@eis2win.co.uk

Mark Faghy

University of Derby

Sport, Outdoor and Exercise Science

Kedleston Road

Derby

UK

DE22 1GB

Tel: 01332592109

Email: M.Faghy@derby.ac.uk

Accepted $13^{\text {th }}$ November 2017 in Journal of Strength and Conditioning Research 


\section{ABSTRACT}

The aim of this study was to examine the impact of weekly swimming training distance upon the ergogenicity of inspiratory muscle training (IMT). Thirty-three youth swimmers were recruited and separated into a LOW and HIGH group based on weekly training distance $\left(\leq 31 \mathrm{~km}^{-1} \mathrm{wk}^{-1}\right.$ and $>41$ $\mathrm{km} \mathrm{wk}^{-1}$, respectively). The LOW and HIGH groups were further subdivided into control and IMT groups for a 6-week IMT intervention giving a total of four groups: $\mathrm{LOW}_{\text {con }} \mathrm{LOW}_{\mathrm{IMT}}, \mathrm{HIGH}_{\mathrm{con}}$, HIGH $_{\text {IMT. }}$ Before and after the intervention period, swimmers completed maximal effort $100 \mathrm{~m}$ and $200 \mathrm{~m}$ front crawl swims, with maximal inspiratory and expiratory mouth pressures (PImax and PEmax, respectively) assessed before and after each swim. IMT increased PImax (but not PEmax) by $36 \%$ in LOW $_{\text {IMT }}$ and $\mathrm{HIGH}_{\mathrm{IMT}}$ groups $(P<0.05)$ but $100 \mathrm{~m}$ and $200 \mathrm{~m}$ swims were faster only in the $\mathrm{LOW}_{\mathrm{IMT}}$ group (3\% and $7 \%$ respectively, $P<0.05)$. Performance benefits only occurred in those training up to $31 \mathrm{~km} \cdot \mathrm{wk}^{-1}$ and indicate that the ergogenicity of IMT is affected by weekly training distance. Consequently, training distances are important considerations, among others, when deciding whether or not to supplement swimming training with IMT.

Key words: breathing, training, adolescents 


\section{INTRODUCTION}

The benefits of pressure-threshold inspiratory muscle training (IMT) upon sport performance are well documented and include improved cycling (17), running (33) and rowing (42) performance. In addition, dyspnea $(34,42,43)$ and exercise blood lactate may be lower during both submaximal exercise $(4,30,41)$ and volitional hyperpnea (3), while recovery time following high intensity repetitive sprint running is shortened (34) and oxygen uptake kinetics are accelerated (4).

Only a few studies have investigated the impact of inspiratory muscle training (IMT) or respiratory muscle training $(\mathrm{RMT})$ on swimming performance $(18,20,31,43)$. These studies employed strength based training protocols, which required swimmers to complete 30-36 training breaths per training session $(18,31,43)$. In contrast only one RMT study (20) adopted an endurance based protocol whereby swimmers were required to complete 30 minutes of exhaustive breathing per session. It is surprising that so few studies have examined the role of breathing muscle training given that swimming presents some unique challenges to the breathing musculature (14), causing their functional weakening. For example, maximal inspiratory mouth pressure, a measure of inspiratory muscle strength, was significantly reduced following $100 \mathrm{~m}$ (1), $200 \mathrm{~m}$ (24,25), $300 \mathrm{~m}$ and $400 \mathrm{~m}$ (39) front crawl swimming, and $200 \mathrm{~m}$ back stroke, breast stroke and butterfly swimming (24).

Supplementing routine swimming training with 6-weeks of IMT or 8-weeks of RMT has been shown to increase inspiratory muscle strength and improve $50 \mathrm{~m}, 100 \mathrm{~m}$ and $200 \mathrm{~m}$ swimming time trial performance $(18,20)$. However, the improvements reported in swimming time trial performance by Kilding et al. (18) and Lemaitre et al. (20), are not universal. Mickleborough, Stager, Chatham, Lindley and Ionescu (31) reported that 12-weeks IMT failed to improve respiratory muscle strength in National and International level swimmers undertaking at least $40 \mathrm{~km} \cdot \mathrm{wk}^{-1}$ of swimming training. Similarly, Wells et al. (43) reported that 12-weeks of RMT improved inspiratory muscle strength but not peak velocity or velocity at the lactate threshold in National standard swimmers completing in excess of 45 $\mathrm{km} \cdot \mathrm{wk}^{-1}$ of training. 
Although Kilding et al. (18) did not report their swimmers average weekly training distance, those examined by Lemaitre et al. (20) swam between $14-34 \mathrm{~km}^{-w^{-1}}$. Consequently, it is possible that differences in weekly training distance were responsible for the conflicting findings of these four studies. Indeed, an increase in training distance is one method recommended to improve performance in youth swimmers (28) and so it is likely that the natural inspiratory muscle conditioning effect induced by immersion and the horizontal body position will be accentuated with longer training distances $(7,8)$. It is therefore possible that supplementing high weekly training distances in swimmers with strengthtraining IMT could fail to induce functional swimming benefits because the relatively high training distance could create a whole body training effect that IMT is unable to supplement. In support of this line of reasoning, both Williams et al. (44) and Sonetti et al. (38) have shown that supplementing routine whole body training with breathing muscle training in well trained runners and cyclists, fails to enhance exercise capacity or peak performance despite increasing respiratory muscle strength. This likely reflects saturation of the perceptual and cardiovascular mechanisms by which IMT is believed to enhance exercise performance (11). These mechanisms include a decrease in the oxygen cost of breathing, which can facilitate oxygen availability to the working muscles (40), a fall in blood lactate arising from an increase in the oxidative capacity of the inspiratory muscles $(3,4)$, a drop in exercising heart rate (11) and a reduction in both breathing and leg discomfort $(11,34,41)$.

The aim of this study was to determine the effect of weekly swimming training distance upon IMT ergogenicity. Specifically, we assessed the impact of IMT upon inspiratory and expiratory muscle strength and sprint swimming time trial performance in trained swimmers completing more than, or less than, $31 \mathrm{~km}^{-1} \mathrm{w}^{-1}$. It was hypothesised that IMT would increase inspiratory muscle strength (but not expiratory muscle strength) regardless of weekly training distance, but that IMT would only enhance swimming time trial performance in those swimming up to $31 \mathrm{~km} \cdot \mathrm{wk}^{-1}$.

\section{METHODS}

Experimental Approach to the Problem

It was our intention to address the impact of weekly training distance (on the basis that weekly session frequency and weekly training duration will dictate this) on the ergogenicity of IMT in well-trained 
youth swimmers. We did this by focusing on swimming performance time trial times and swimming kinematics in response to IMT in male and female swimmers with different training histories.

To do this trained swimmers undertaking different weekly training distances were recruited and separated into LOW and HIGH training distance groups. Swimmers were then further subdivided into IMT and control groups: thus each training distance permutation contained a control group. Training distance was kept consistent throughout the 6-week period with all LOW swimmers undertaking the same overall weekly training program and all HIGH groups undertaking the same overall weekly training program: this was confirmed by the respective coaches. It was not our intention to control how the swimming training distance was achieved as this would require selecting trained swimmers and changing their routine program (which would be unreflective of their actual training environment), or selecting untrained swim-able individuals and prescribing a swimming and IMT training program. Both of these approaches have the potential to confound swimming performance irrespective of IMT. Consequently, the approach we adopted, although not without limitation, was chosen to maximise ecological validity and provide swimmers and coaches with directly applicable information regarding the usefulness of IMT inclusion into routine swimming training.

Subjects

Thirty-three well trained youth swimmers (18 males, 15 females) volunteered for this study (including one asthmatic who did not require any medication for athma during the study). Swimmers were initially separated into two groups based upon their weekly training distance defined as either low (LOW) or high (HIGH): the selection of training distances were consistent with those reported in similar studies $(20,31,43)$. Throughout the 6-week period the swimming coaches of the LOW and HIGH groups confirmed that the overall swimming training program was the same for both IMT and control swimmers. Descriptive data for the LOW and HIGH groups as a whole are in Table 1. Participants provided informed written consent after being informed of the benefits and risks of the study, and local Institutional ethical approval was obtained before the start of the study. 
**Table 1 about here**

Study overview

Following a pulmonary and respiratory muscle familiarisation session, all participants completed a racepaced $100 \mathrm{~m}$ and $200 \mathrm{~m}$ front crawl swim (time trial tests) in their usual indoor training pool. The LOW and HIGH groups were then further separated with half the swimmers in the LOW and HIGH groups randomly assigned IMT (LOW IMT $\mathrm{n}=9$; $\mathrm{HIGH}_{\text {IMT }} \mathrm{n}=8$ ) and the remaining swimmers serving as controls $\left(\mathrm{LOW}_{\mathrm{CON}} \mathrm{n}=9\right.$; $\left.\mathrm{HIGH}_{\mathrm{CON}} \mathrm{n}=7\right)$. Thus, there were a total of four experimental groups: $\mathrm{LOW}_{\text {con }}, \mathrm{LOW}_{\text {IMT }}, \mathrm{HIGH}_{\text {con }}$ and $\mathrm{HIGH}_{\mathrm{IMT}}$. The IMT regimen was identical for both groups, see below.

Following the time trial tests, those in the $\mathrm{LOW}_{\mathrm{IMT}}$ and $\mathrm{HIGH}_{\mathrm{IMT}}$ groups undertook their usual training plus 6-weeks of IMT. Those in the $\mathrm{LOW}_{\text {con }}$ and $\mathrm{HIGH}_{\text {con }}$ continued with their usual training only. All swimmers then repeated the time trial and respiratory muscle function tests in the same indoor pool as their pre IMT time trial tests and following the same warm-up.

Procedures

Forced vital capacity (FVC) and forced expired volume in one second $\left(\mathrm{FEV}_{1}\right)$ were measured (MicroLab MK8 digital spirometer, CareFusion, Kent, UK), in a seated position and from total lung capacity pre IMT for descriptive purposes of lung function (Table 1). Maximal inspiratory and expiratory mouth pressures (PImax and PEmax, respectively) were measured upright with the nose occluded on poolside using a hand-held respiratory pressure metre (RPM, Micro Medical, Rochester, UK). PImax and PEmax were measured pre (before the warm-up) and post each performance test from residual volume and total lung capacity respectively.

Each swimmer completed a maximum effort $100 \mathrm{~m}$ and $200 \mathrm{~m}$ front crawl swim from a dive start, in a counterbalanced order and on separate occasions within one week of each other. Swimming time was recorded per swim using a stop watch, and in the case of the $200 \mathrm{~m}$ swim, per $100 \mathrm{~m}$ partial also. Clean 
swimming velocity and stroke rate (SR) were recorded per $100 \mathrm{~m}$ and $200 \mathrm{~m}$ swim (Finis stop watch with base count 3 function) using a $12.5 \mathrm{~m}$ central pool zone, and expressed per $100 \mathrm{~m}$ partial of the $200 \mathrm{~m}$ swims. Stroke rate was converted from total stroke cycles to cycles per second $(\mathrm{Hz})$ using achieved velocity $\left(\mathrm{m}^{-1}\right)$ and then multiplied by 60 to achieve cycles per minute (cycles $\left.\mathrm{min}^{-1}\right)(6,21)$. Stroke length (SL: $\mathrm{mcycle}^{-1}$ ) was then calculated as achieved velocity divided by $\mathrm{SR}$ in $\mathrm{Hz}(5,6)$.

IMT was performed (POWERbreathe, POWERbreathe International Ltd, UK; Power Lung, Power Lung, USA) twice daily, $7 \mathrm{~d}^{-w^{-1}}$ for 6-weeks. Each session consisted of 30 breaths at an intensity equivalent to 50\% PImax $(11,16,18,33)$. After the initial setting of training loads, participants were instructed by an investigator to increase periodically the load on the inspiratory muscle trainer so that 30 breaths could only just be completed (18). Those assigned to the control condition undertook their usual (coach prescribed) training only.

\section{Statistical Analyses}

Baseline (i.e. pre-IMT) descriptive data (age, mass, stature, FVC, FEV 1 , FEV $1 / F V C$, PImax, PEmax, $100 \mathrm{~m}$ and $200 \mathrm{~m}$ swimming time trial times) were first assessed for normality and then compared between LOW (pooled $\mathrm{LOW}_{\text {con }}$ and $\mathrm{LOW}_{\mathrm{IMT}}$ ) and $\mathrm{HIGH}$ (pooled $\mathrm{HIGH}_{\text {con }}$ and $\mathrm{HIGH}_{\mathrm{IMT}}$ ) groups as a whole using independent samples t-tests and a Mann Whitney $U$ test for age. Baseline and post IMT PImax and PEmax were recoded as the highest value regardless of time trial test.

Mixed model repeated measures ANOVAs were used to assess for differences in PImax, inspiratory muscle fatigue (IMF), expiratory muscle fatigue (EMF), PEmax, swimming time, velocity, SR and SL per $100 \mathrm{~m}$ and $200 \mathrm{~m}$ swim in $\mathrm{LOW}_{\text {con }}, \mathrm{LOW}_{\mathrm{IMT}}, \mathrm{HIGH}_{\mathrm{con}}$ and $\mathrm{HIGH}_{\mathrm{IMT}}$ groups. In the case of the 200 $\mathrm{m}$ swim, this was also extended to per $100 \mathrm{~m}$ partial. IMF and EMF were defined by the transient reduction $\left(\mathrm{cmH}_{2} \mathrm{O}\right)$ in mouth pressure pre- (before the warm-up) vs post- exercise. 
Post hoc, repeated measures ANOVAs with Bonferroni adjustments were used to assess differences in swimming time, velocity, SR and SL for all groups, per $200 \mathrm{~m}$ swim. Paired and independent samples t-tests assessed differences in swimming time, velocity and SR for the $100 \mathrm{~m}$ swim pre and post IMT. Between groups ANOVA's with Bonferroni adjustments and independent t-tests were used to assess for differences in the highest recorded PImax and PEmax values pre and post IMT between groups.

$P$ was set at 0.05 and analyses were undertaken using IBM SPSS statistics version 22. Effect sizes were calculated using Cohen's $d$ for parametric data with an effect size of 0.2 deemed small, 0.6 moderate, 1.2 large, 2.0 very large and 4.0 extremely large (15). For non-parametric data, $r$ was used, whereby $r$ is the $\mathrm{z}$ score divided by the square root of the total number of observations. A value of 0.1 is deemed small, 0.3 medium and 0.5 and above large (12). Data are presented as mean and standard deviation (SD) unless otherwise stated.

\section{RESULTS}

Respiratory muscle strength

Baseline PImax and PEmax were similar between all groups. PEmax was unaffected by IMT, but PImax did increase $(\mathrm{F}=105.142, P<0.001)$ after IMT. The biggest improvement in PImax was seen in the $\mathrm{LOW}_{\text {IMT }}(98 \pm 4 \%$ IMT compliance $)$ and $\mathrm{HIGH}_{\mathrm{IMT}}(91 \pm 3 \%$ IMT compliance) groups $(\mathrm{F}=$ $16.355, P<0.001, d=0.97-1.29)$ (figure 1).

**Figure 1 about here**

IMF was highly variable amongst swimmers (Figure 2). These differences in IMF magnitude were not significant and were unaffected by IMT. There was no evidence of EMF. 
**Figure 2 about here**

Swimming time and velocity

Pre IMT $100 \mathrm{~m}$ and $200 \mathrm{~m}$ swimming times were on average $14 \%$ faster $(9.1 \mathrm{~s}$ and $20.8 \mathrm{~s}$, respectively) $(P<0.001)$ in the $\mathrm{HIGH}$ (pooled $\mathrm{HIGH}_{\text {con }}$ and $\mathrm{HIGH}_{\mathrm{IMT}}$ ) compared with $\mathrm{LOW}$ (pooled $\mathrm{LOW}_{\text {con }}$ and LOW $_{\text {IMT }}$ ) group swimmers (Table 1). IMT improved $100 \mathrm{~m}(\mathrm{~F}=14.455, P<0.001$, power $=0.954)$ and $200 \mathrm{~m}(\mathrm{~F}=21.108, P<0.001$, power $=0.993)$ swimming times (and hence velocity) in the $\mathrm{LOW}_{\mathrm{IMT}}$ group (100 m: $d=0.32 ; 200 \mathrm{~m}: d=0.64)$ but not the $\mathrm{HIGH}_{\mathrm{IMT}}$, $\mathrm{LOW}_{\text {con }}$ or $\mathrm{HIGH}_{\text {con }}$ groups (Table 2 ). $100 \mathrm{~m}$ and $200 \mathrm{~m}$ swimming times were slower following IMT in $\mathrm{HIGH}_{\mathrm{IMT}}$ and $\mathrm{HIGH}_{\mathrm{con}}$ respectively $(P<0.05 ; 100 \mathrm{~m}: d=0.65 ; 200 \mathrm{~m}: d=0.59)$.

The $1^{\text {st }}$ and $2^{\text {nd }} 100 \mathrm{~m}$ partials of the $200 \mathrm{~m}$ differed between the HIGH and LOW groups $(\mathrm{F}=10.844$, $P=0.003$, power $=0.889)$. The $1^{\text {st }} 100 \mathrm{~m}(d=0.39)$ and $2^{\text {nd }} 100 \mathrm{~m}(d=0.24)$ partials were faster after IMT in the $\operatorname{LOW}_{\text {IMT }}$ group $(P<0.05)$. The $1^{\text {st }} 100 \mathrm{~m}(d=-0.58)$ and $2^{\text {nd }} 100 \mathrm{~m}(d=-0.58)$ partials were slower $(P<0.05)$ after the intervention in the $\mathrm{HIGH}_{\text {con }}$ group (Table 2$)$.

The improvement in PImax post IMT in the LOW $_{\text {IMT }}$ group was not correlated with the change in 100 $\mathrm{m}$ or $200 \mathrm{~m}$ swimming times pre and post IMT $(P>0.05)$.

**Table 2 about here**

Stroke rate and length

$100 \mathrm{~m}(\mathrm{~F}=8.298, P=0.008$, power $=0.789)$ and $200 \mathrm{~m}(\mathrm{~F}=35.578, P<0.001$, power $=1.000) \mathrm{SR}$ was higher in the $\mathrm{HIGH}_{\text {con }}$ and $\mathrm{HIGH}_{\text {IMT }}$ groups than the $\mathrm{LOW}_{\text {con }}$ and $\mathrm{LOW}_{\text {IMT }}$ groups pre and post IMT (Table 2). No differences were observed between partials $(P>0.05)$ although SR was lower in $\mathrm{HIGH}_{\mathrm{con}}$ per partial $\left(1^{\text {st }} 100 \mathrm{~m}: d=0.84 ; 2^{\text {nd }} 100 \mathrm{~m}: d=0.75\right)$ following IMT, and was lower in the $2^{\text {nd }} 100 \mathrm{~m}$ 
partial for the HIGH IMT group regardless of whether assessed pre or post IMT (pre IMT: $d=0.78$; post IMT: $d=0.67)(\mathrm{F}=18.257, P<0.001$, power $=1.000$, Table 2$)$.

$100 \mathrm{~m}$ SL was unaffected by IMT status $(P>0.05)$. Although SL was similar in the $\mathrm{HIGH}_{\mathrm{IMT}}$ and $\mathrm{LOW}_{\mathrm{IMT}}$ groups the tendency for SL to be lower in the $\mathrm{HIGH}_{\text {con }}$ group compared with the $\mathrm{LOW}_{\text {con }}$ group pre and post IMT $(d=0.40-0.52)$ just missed statistical significance $(\mathrm{F}=4.096, P=0.054$, power $=$ $0.493)$. SL in the $2^{\text {nd }} 100 \mathrm{~m}$ partial of the $200 \mathrm{~m}$ was consistently shorter than the $1^{\text {st }} 100 \mathrm{~m}$ partial in all groups $(\mathrm{F}=23.748, P<0.001$, power $=0.997, d=0.12-0.36)$. However, IMT did not affect SL and no differences were observed between the LOW and HIGH groups $(P>0.05$; Table 2).

\section{DISCUSSION}

The aim of this study was to investigate the effect of weekly training distance upon the ergogenicity (100 $\mathrm{m}$ and $200 \mathrm{~m}$ swimming time trial tests) of 6-weeks pressure threshold IMT. The main findings were that IMT increased PImax, but swimming time (and hence velocity) were only improved when swimming training distance was no greater than $31 \mathrm{~km} \cdot \mathrm{wk}^{-1}$.

Past studies have shown that PImax of trained swimmers varies between $83-146 \mathrm{cmH}_{2} \mathrm{O}$ in those aged 13-17 years $(20,24,27,35,39,43)$ and between $123-148 \mathrm{cmH}_{2} \mathrm{O}$ in individuals aged 19-30 years $(1,16$, $22,25,26)$; although one study reported substantially higher pressures of $182 \pm 27 \mathrm{cmH}_{2} \mathrm{O}$ in swimmers aged 18.2 \pm 1.6 years (31). Our baseline PImax data (Table 1) is therefore consistent with that of youth swimmers, and substantially greater than their age-predicted PImax: $144 \pm 29 \%$ for LOW (pooled $\mathrm{LOW}_{\text {con }}, \mathrm{LOW}_{\mathrm{IMT}}$ ) and $142 \pm 25 \%$ for $\mathrm{HIGH}$ (pooled $\mathrm{HIGH}_{\mathrm{con}}, \mathrm{HIGH}_{\mathrm{IMT}}$ ) groups (45).

IMT has been shown to increase PImax by 9-17\% following only 6-weeks of IMT (18) or RMT (43), by $\sim 40 \%$ following 8 -weeks of RMT (20) and by as much as $64 \%$ following 12 -weeks of RMT (43). We observed a 36\% improvement in PImax following 6-weeks of IMT. However, as the LOW $_{\text {con }}$ and $\mathrm{HIGH}_{\text {con }}$ groups collectively improved PImax by $9 \%$, which most likely reflects a learning effect, we 
cannot rule out the possibility that the $\mathrm{LOW}_{\mathrm{IMT}}$ and $\mathrm{HIGH}_{\mathrm{IMT}}$ groups experienced a similar phenomenon.

The $100 \mathrm{~m}$ and $200 \mathrm{~m}$ performance tests were $3 \%$ and $7 \%$ faster $(P<0.05)$ following IMT in the LOW $_{\text {IMT }}$ group, which represented a lower standard group of swimmers However, these improvements were not correlated with the increase in PImax $(P>0.05)$. We are not the first to observe such a disconnect and evidence in cycling and running suggests that improved performance following acute or chronic improvements in PImax is not due to PImax per se $(10,11,17)$. Rather, it seems likely that the improved $100 \mathrm{~m}$ and $200 \mathrm{~m}$ swimming times of the $\mathrm{LOW}_{\text {IMT }}$ group following IMT reflects a number of mechanistic changes secondary to the IMT-induced structural and functional changes occurring in the inspiratory muscles $(11,17,34)$. These might include an increase in the oxidative capacity of the inspiratory muscles including enhanced lactate kinetics $(3,4)$, and a fall in the oxygen cost of breathing. The latter would facilitate oxygen availability to the working muscles (40) and potentially reduce the perception of both breathlessness and limb muscle discomfort $(11,34,41)$. Furthermore, given that the magnitude of increase in PImax does not dictate the magnitude of exercise improvement, this might partly explain why IMF is not necessarily reduced after IMT (11) or correlated with performance following RMT (42). In support of this we found that IMT had no impact on the magnitude of IMF experienced by swimmers. However, it should also be noted that while IMF did occur in some swimmers, it was highly variable (Figure 2).

Our swim time and velocity data suggest that training distance is a key factor in determining the ergogenecity of IMT. Our data also supports the contradictory observations reported in the literature. For example, Kilding et al. (18) and Lemaitre et al. (20) found that $50 \mathrm{~m}, 100 \mathrm{~m}$ and $200 \mathrm{~m}$ time trial swims were $1.7 \%$ to $4 \%$ faster following 6-weeks IMT or 8-weeks RMT, whereas Wells et al. (43) found that IMT did not enhance peak swimming velocity when training distance was $45-88 \mathrm{~km} \cdot \mathrm{wk}^{-1}$. The swimmers recruited by Wells and colleagues (43) were of National standard, whereas Kilding et al. (18) and Lemaitre et al. (20) examined club-level and well-trained swimmers, respectively. Although Kilding et al. (18) did not provide details of their swimmers weekly training distance, Lemaitre et al. (20) reported that their swimmers completed $14-34 \mathrm{~km}^{-1} \mathrm{wk}^{-1}$, which was substantially 
lower than that reported by Wells et al. (43) and is consistent with the distances completed by the $\mathrm{LOW}_{\text {con }}$ and $\mathrm{LOW}_{\mathrm{IMT}}$ groups of the present study. Furthermore, it is interesting to note that pre IMT/RMT $200 \mathrm{~m}$ and $100 \mathrm{~m}$ swimming times were around 130-133 s and $64 \mathrm{~s}$ respectively in the studies of Kilding et al. (18) and Lemaitre et al. (20), which are faster than the $200 \mathrm{~m}$ and $100 \mathrm{~m}$ swimming times of $\mathrm{LOW}_{\text {con }}$ and $\mathrm{LOW}_{\mathrm{IMT}}$ groups, but slower than the $\mathrm{HIGH}_{\mathrm{con}}$ and $\mathrm{HIGH}_{\mathrm{IMT}}$ groups (Table 2). However, based on our findings it would be unwise to attribute the inability of IMT to improve performance in the $\mathrm{HIGH}_{\mathrm{IMT}}$ group to an absolute training distance threshold phenomenon that once exceeded means that IMT is unable to enhance performance. Because both the $\mathrm{HIGH}_{\mathrm{IMT}}$ and $\mathrm{HIGH}_{\text {con }}$ groups tended to swim more slowly after the 6 week intervention (Table 2), we cannot exclude the possibility that swim training volume per se resulted in a state of holistic fatigue or overreaching compared with the LOW groups. Although LOW and HIGH group swimmers were in endurance and high volume focused periods at the time of testing (preparatory for the LOW groups and specific preparatory for the HIGH groups), HIGH group swimmers completed an additional $66-246 \mathrm{~km}$ than LOW group swimmers over the 6 week intervention. Indeed, González-Boto et al. (13) found that increasing training distance from $28-32 \mathrm{~km}$ to $45 \mathrm{~km}$ or greater in Regional standard swimmers (age $15.5 \pm 7.5$ years) over a 6 week period significantly increased the signs of overreaching (diminished recovery and elevated stress). These signs only reversed when training distance was reduced to $39 \mathrm{~km}$ or less. Thus, it is possible that the administration of IMT in the HIGH $_{\text {IMT }}$ group coincided with a period of overreaching masking any potential IMT mediated benefits.

Unfortunately the current study is unable to identify how $100 \mathrm{~m}$ and $200 \mathrm{~m}$ velocities increased after

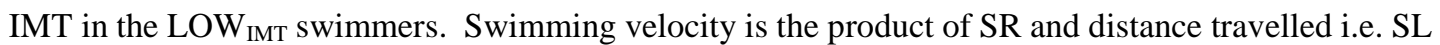
and at faster velocities typically increases by increasing SR and decreasing SL $(9,36,37)$. The faster swimming $100 \mathrm{~m}$ and $200 \mathrm{~m}$ velocities observed in the HIGH compared with LOW groups were consistent with this (Table 2). However, the increase in $100 \mathrm{~m}$ and $200 \mathrm{~m}$ velocities after IMT in the $\mathrm{LOW}_{\text {IMT }}$ group were not associated with an increase in SR. Because of the relationship between SR and SL, velocity will increase if the force exerted per stroke, and hence distance travelled, increases without an accompanying rise in SR (9). But SL was also unchanged in the $\mathrm{LOW}_{\mathrm{IMT}}$ group after IMT (Table 2). Our findings are therefore difficult to explain. It is possible that the non-significant increase in SR $(d=-0.24)$ lead to an increase in 100 m mean velocity, but this does not explain the increased 
mean $200 \mathrm{~m}$ velocity. Indeed, the increase in velocity was mainly due to improvements observed in the $1^{\text {st }} 100 \mathrm{~m}$ partial $(P<0.05, d=-0.30)$, yet SR and SL were unchanged following IMT. Only during the $2^{\text {nd }} 100 \mathrm{~m}$ partial did SL exhibit a tendency to increase after IMT $(P>0.05, d=-0.10)$. We have no satisfactory explanation for this and unfortunately no other swimming IMT/RMT studies have examined the impact of IMT/RMT on SR or SL. It is conceivable that the measurement methods adopted were simply not sensitive enough to detect IMT-induced changes or partition the effect of IMTinduced, from swim-training induced, changes. Indeed, there was a non-significant tendency for swim time to improve in the $\mathrm{LOW}_{\text {con }}$ group after IMT. This might indicate that IMT in the $\mathrm{LOW}_{\text {IMT }}$ group supplemented the swim-training induced changes making them statistically significant. Given that SR, SL and velocity provide no information about technique or arm coordination measures $(36,37)$, analysis of arm coordination parameters (e.g. entry, pull, push and recovery phases) might prove more revealing than simply SR and SL when investigating the impact of IMT on stroke characteristics and in-turn velocity.

In conclusion, as $100 \mathrm{~m}$ and $200 \mathrm{~m}$ swimming times, and hence velocity, improved after IMT only when swim-training distance did not exceed $31 \mathrm{~km} \cdot \mathrm{wk}^{-1}$, our data indicate that IMT should not be advocated as a blanket training adjunct to all swimmers. Even though swimming performance did not improve once training distance exceeded $41 \mathrm{~km} \cdot \mathrm{wk}^{-1}$, this training distance is unlikely to reflect a fixed threshold value in determining the ergogenicity of IMT. Rather, the independent effects of the competitive level of swimmers, training volume, training cycle phase and other routine training considerations more likely, and collectively, dictate the ergogenicity of IMT.

Furthermore, it is important to reiterate that the swimmers in the current study were adolescent and therefore unlikely to have reached physically maturity at the time of testing $(19,28)$. Caution is therefore advised if applying our findings to Senior and Masters swimmers who are likely to be fully mature and better able to cope with the physiological, biomechanical and psychological demands associated with the greater weekly training distances routinely undertaken (28).

\section{PRACTICAL APPLICATIONS}


6-weeks of pressure threshold IMT significantly increased PImax in well-trained youth swimmers although this did not automatically translate into improved swimming time trial performance. $100 \mathrm{~m}$ and $200 \mathrm{~m}$ swim times following IMT improved only in adolescent swimmers who undertook no more than $31 \mathrm{~km} \cdot \mathrm{wk}^{-1}$ of swim training. However, the merits of supplementing swimming training with IMT should not be based on weekly training distance in isolation but rather on a combination of the competitive level of swimmers, swim-training and IMT. 


\section{REFERENCES}

1. Brown, S, and Kilding, AE. Exercise-induced inspiratory muscle fatigue during swimming: the effect of race distance. J Strength Cond Res 25: 1204-1209, 2011.

2. Brown, PI, Johnson, MA, and Sharpe, GR. Determinants of inspiratory muscle strength in healthy humans. Respir Physiol Neurobiol 196: 50-55, 2014.

3. Brown, PI, Sharpe, GR, and Johnson, MA. Inspiratory muscle training reduces blood lactate concentration during volitional hyperpnoea. Eur J Appl Physiol 104: 111-117, 2008.

4. Brown, PI, Sharpe, GR, and Johnson, MA. Inspiratory muscle training abolishes the blood lactate increase associated with volitional hyperpnoea superimposed on exercise and accelerates lactate and oxygen uptake kinetics at the onset of exercise. Eur J Appl Physiol 112: 2117-2129, 2012.

5. Cardelli, C, Chollet, D, and Lerda, R. Analysis of the 100-m front crawl as a function of skill level in non-expert swimmers. J Hum Movement Stud 36: 51-74, 1999.

6. Cardelli, C, Lerda, R, and Chollet, D. Analysis of breathing in the crawl as a function of skill and stroke characteristics. Percept Motor Skill 90: 979-987, 2000.

7. Clanton, TL, Dixon, GF, Drake, J, and Gadek, JE. Effects of swim training on lung volumes and inspiratory muscle conditioning. J Appl Physiol 62: 39-46, 1987.

8. Cordain, L, and Stager, J. Pulmonary structure and function in swimmers. Sports Med 6: 271$278,1988$.

9. Craig, $\mathrm{AB}$, and Pendergast, DR. Relationship of stroke rate, distance per stroke, and velocity in competitive swimming. Med Sci Sports Exerc 11: 278-283, 1979.

10. Dunham, C, and Harms, CA. Effects of high-intensity training on pulmonary function. Eur J Appl Physiol 112: 3061-3068, 2012.

11. Faghy, MA, and Brown, PI. Training the inspiratory muscles improves running performance when carrying a $25 \mathrm{~kg}$ thoracic load in a backpack. Eur J Sports Sci 16: 585-594, 2016.

12. Field, AF. Discovering Statistics Using IBM SPSS Statistics. London: Sage 2013

13. González-Boto, R, Salguero, A, Tuero, C, González-Gallego, J, and Márquez, S. Monitoring the effects of training load changes on stress and recovery in swimmers. J Physiol Biochem 64: 19-26, 2008. 
14. Hong, SK, Cerretelli, P, Cruz, JC, and Rahn, H. Mechanics of respiration during submersion in water. J Appl Physiol 27: 535-538, 1969.

15. Hopkins, WG, Marshall, SW, Batterham, AM, and Hanin, J. Progressive statistics for studies in sports medicine and exercise science. Med Sci Sports Exerc 41: 3-12, 2009.

16. Jakovljevic, DG, and McConnell, AK. Influence of different breathing frequencies on the severity of inspiratory muscle fatigue induced by high-intensity front crawl swimming. J Strength Cond Res 23: 1169-1174, 2009.

17. Johnson, MA, Sharpe, GR, and Brown, PI. Inspiratory muscle training improves cycling timetrial performance and anaerobic work capacity but not critical power. Eur J Appl Physiol 101: 761-770, 2007. doi

18. Kilding, AE, Brown, S, and McConnell, AK. Inspiratory muscle training improves 100 and 200 m swimming performance. Eur J Appl Physiol 108: 505-511, 2010.

19. Kojima, K, Jamison, PL, and Stager, JM. Multi-age-grouping paradigm for young swimmers. J Sports Sci 30: 313-320, 2012.

20. Lemaitre, F, Coquart, JB, Chavallard, F, Castres, I, Mucci, P, Buchheit, M, Costalat, G, and Chollet, D. Effect of additional respiratory muscle endurance training in young well-trained swimmers. J Sports Sci Med 12: 630-638, 2013.

21. Lerda, R, and Cardelii, C. Breathing and propelling in crawl as a function of skill and swim velocity. Int J Sports Med 24: 75-80, 2003.

22. Lomax, M, and Castle, S. Inspiratory muscle fatigue significantly affects breathing frequency, stroke rate and stroke length during $200 \mathrm{~m}$ front crawl swimming. J Strength Cond Res 25: 2691-2695, 2011.

23. Lomax, M, Grant, I, and Corbett, J. Inspiratory muscle warm-up and inspiratory muscle training: separate and combined effects on intermittent running to exhaustion. J Sports Sci 29: 563-569, 2011.

24. Lomax, M, Iggleden, C, Tourell, A, Castle, S., and Honey J. Inspiratory muscle fatigue after race-paced swimming is not restricted to the front crawl stroke. J Strength Cond Res 26: 2729$2733,2012$.

25. Lomax, M, and McConnell, AK. Inspiratory muscle fatigue in swimmers after a single $200 \mathrm{~m}$ swim. J Sports Sci 21: 659-664, 2003. 
26. Lomax, M, Tasker, L, and Bostanci, O. An electromyographic evaluation of dual role breathing and upper body muscles in response to front crawl swimming. Scand J Med Sci Sports 25: e472-e478, 2015.

27. Lomax, M, Thomaidis, SP, Iggleden, C, Toubekis, AG, Tiligadas, G, Tokamkidis, SP, Oliveira, RC, and Costa, AM. The impact of swimming speed on respiratory muscle fatigue during front crawl swimming: a role for critical velocity? Int J Swimming Kin, 2: 3-12, 2013.

28. Maglischo, EW. Swimming Even Faster. California: Mayfield Publishing Company 1993.

29. McConnell, AK. Lung and respiratory muscle function. In: Sport and Exercise Physiology Testing Guidelines (BASES) Vol 2: Exercise and Clinical Testing. E.M. Winter, A.M. Jones, R.C.R. Davison, P.D. Bromley and T.H. Mercer, eds. Abingdon: Routledge, 2007. Pp. 63-75.

30. McConnell, AK, and Sharpe, GR. The effect of inspiratory muscle training upon maximum lactate steady-state and blood lactate concentration. Eur J Appl Physiol 94: 277-284, 2005.

31. Mickleborough, TD, Stager, JM, Chatham, K, Lindley, MR, and Ionescu, AA. Pulmonary adaptations to swim and inspiratory muscle training. Eur J Appl Physiol 103: 635-646, 2008.

32. Potdevin F, Bril, B, Sidney, M, and Pelayo, P. Stroke frequency and arm coordination in front crawl swimming. Int J Sports Med 27: 193-198, 2006.

33. Romer, LM, and McConnell, AK. Specificity and reversibility of inspiratory muscle training. Med Sci Sports Exerc 35: 237-244, 2003.

34. Romer, LM, McConnell, AK, and Jones, DA. Effects of inspiratory muscle training upon recovery time during high intensity, repetitive sprint activity. Int J Sports Med 23: 353-360, 2002.

35. Santos, MARC, Pinto, ML, Sant'Anna, CC, and Bernhoeft, M. Maximal respiratory pressures among adolescent swimmers. Rev Port Pneum 17: 66-70, 2011.

36. Seifert, L, Chollet, D, and Bardy, BG. Effect of swimming velocity on arm coordination in the front crawl: a dynamic analysis. J Sports Sci 22: 651-660, 2004.

37. Seifert, L, Toussaint, HM, Alberty, M, Schnitzler, C, and Chollet, D. Arm coordination, power, and swim efficiency in national and regional front crawl swimmers. Hum Movement Sci 29: 426-439, 2010. 
38. Sonetti, DA, Wetter, TJ, Pegelow, DF, and Dempsey, JA. Effects of respiratory muscle training versus placebo on endurance exercise performance. Respiration Physiol 127: 185-199, 2001.

39. Thomaidis, SP, Toubekis, AG, Mpousmoukilia, SS, Douda, HT, Antoniou, PD, and Tokmakidis, SP. Alterations in maximal inspiratory mouth pressure during a 400-m maximum effort front-crawl swimming trial. J Sports Med Phys Fitness 49: 194-200, 2009.

40. Turner, LA, Teckenburg-Lung, SL, Chapman, RF, Stager, JM, Wilhite, DP, and Mickleborough, TD. Inspiratory muscle training lowers the oxygen cost of voluntary hyerpnea. J Appl Physiol 112: 127-134, 2012.

41. Verges, S, Lenherr, O, Haner, AC, Schulz, C, and Spengler, CM. Increased fatigue resistance of respiratory muscles during exercise after respiratory muscle endurance training. Am J Physiol-REG I 292: R1246-R1253, 2007.

42. Volianitis, S, McConnell, AK, Koutedakis, Y, McNaughton, L, Backx, L, and Jones DA. Inspiratory muscle training improves rowing performance. Med Sci Sports Exerc 33: 803-809, 2001.

43. Wells, GD, Plyley, M, Thomas, S, Goodman, L., and Duffin, J. Effects of concurrent inspiratory and expiratory muscle training on respiratory and exercise performance in competitive swimmers. Eur J Respir Physiol 94: 527-540, 2005.

44. Williams, JS, Wongsathikun, J, Boon, SM, and Acevedo, EO. Inspiratory muscle training fails to improve endurance capacity in athletes. Med Sci Sports Exerc 34: 1194-1198, 2002.

45. Wilson, SH, Cooke, NT, Edwards, RHT, and Spiro, SG. Predicted normal values for maximal respiratory pressures in caucasian adults and children. Thorax 39: 535-538, 1984. 


\section{ACKNOWLDGEMENTS}

We thank all the swimmers and their coaches who volunteered for this study 
Figure 1. Highest PImax before and after IMT

Note. Filled bars $=$ pre IMT; open bars $=$ post IMT. $*(P<0.05)$ different to pre IMT within group; ${ }^{\S}(P$

$<0.01)^{\S}(P<0.05)$ pre and post IMT delta change different to $\mathrm{HIGH}_{\mathrm{IMT}}$; $(P<0.05)$ pre and post IMT delta change different to $\mathrm{LOW}_{\mathrm{IMT}}$ 


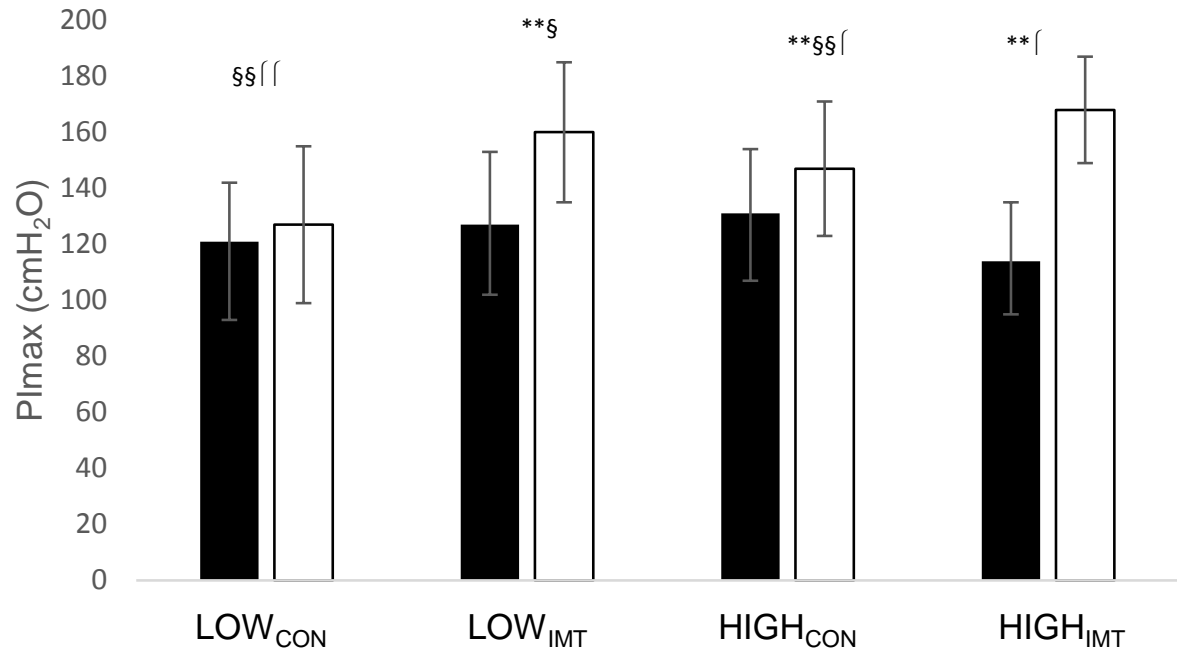


Figure 2. IMF following $100 \mathrm{~m}$ (A) and $200 \mathrm{~m}$ (B) swimming time trial tests before and after IMT

Note. Filled bars $=$ pre IMT; open bars $=$ post IMT 
A

A 50

产 40

દ 30

윽 20

范 10

है

हू -10

$\frac{\pi}{\frac{\pi}{0}}-20$
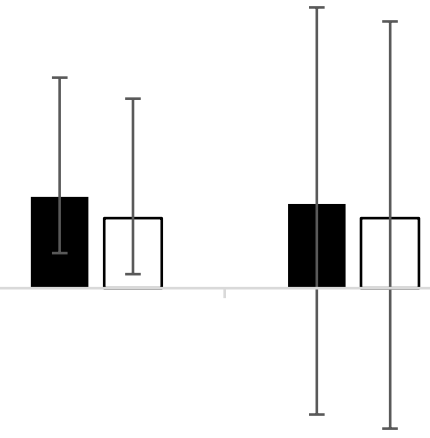

$\Gamma^{I}$

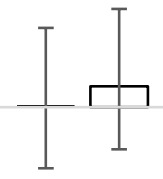

$-30$

B

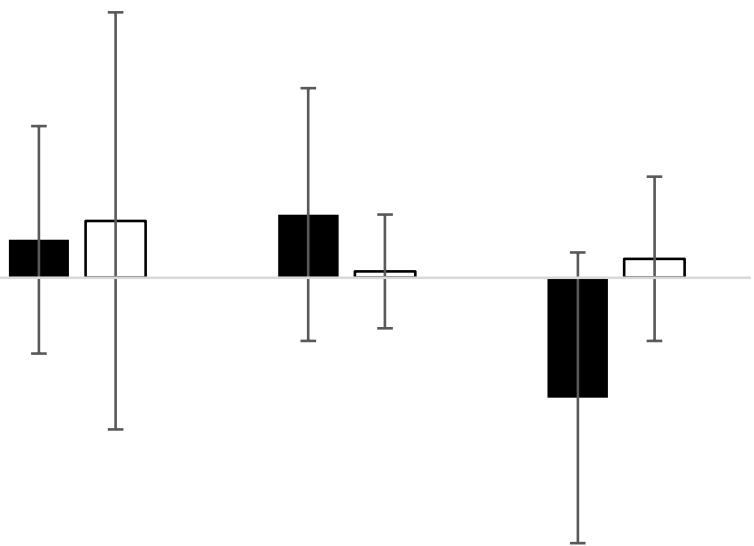

LOW

LOWIMT

HIGHCON

HIGHIMT 
Table 1. Baseline participant and swimming descriptive data for LOW and HIGH group swimmers: mean \pm SD

\begin{tabular}{|c|c|c|c|c|}
\hline Parameter & LOW & HIGH & $P$ & $\mathrm{~d}$ or $r$ \\
\hline $\mathrm{n}$ & 18 & 15 & l & I \\
\hline Males (number) & 11 & 7 & l & / \\
\hline Weekly training distance $(\mathrm{km})$ & $15-31$ & $42-56$ & l & / \\
\hline Weekly training duration (hours) & 10.5 & $14-19$ & I & I \\
\hline Weekly session frequency & 6 & $8-9$ & l & l \\
\hline Competitive experience (years) & $5-8$ & $3-4$ & l & / \\
\hline Standard & National & International & I & I \\
\hline Training period & Preparatory & Specific preparatory & l & l \\
\hline 100 m swimming time (s) & $66.4 \pm 6.6$ & $57.3 \pm 4.1$ & $<.001$ & large effect \\
\hline 200 m swimming time (s) & $146.5 \pm 13.8$ & $125.7 \pm 8.1$ & $<.001$ & large effect \\
\hline Age (years) & $16 \pm 3$ & $16 \pm 1$ & .957 & no effect \\
\hline Mass (kg) & $65.9 \pm 13.7$ & $65.2 \pm 8.3$ & .851 & no effect \\
\hline Stature (m) & $1.76 \pm 0.12$ & $1.75 \pm 0.11$ & .828 & no effect \\
\hline $\operatorname{PImax}\left(\mathrm{cmH}_{2} \mathrm{O}\right)$ & $124 \pm 22$ & $123 \pm 24$ & .893 & no effect \\
\hline PEmax $\left(\mathrm{cmH}_{2} \mathrm{O}\right)$ & $135 \pm 42$ & $133 \pm 28$ & .845 & no effect \\
\hline FVC (1) & $5.23 \pm 1.22$ & $4.48 \pm 1.25$ & .090 & moderate effect \\
\hline $\mathrm{FEV}_{1}\left(1 \cdot \mathrm{s}^{-1}\right)$ & $4.40 \pm 1.14$ & $3.94 \pm 1.08$ & .243 & small/moderate effect \\
\hline $\mathrm{FEV}_{1} / \mathrm{FVC}(\%)$ & $84 \pm 8$ & $88 \pm 6$ & .123 & moderate effect \\
\hline
\end{tabular}

Note. Italic $=$ non-parametric analyses. Highest PImax and PEmax regardless of trial. $\mathrm{T}$ and $\mathrm{U}=$ independent $\mathrm{t}$-test and Mann Whitney $\mathrm{U}$ test,

respectively between LOW and HIGH groups. $d$ and $r=$ effect sizes. See text for abbreviations. 